\title{
A FURTHER STUDY OF THE ANTIRACHITIC FACTOR IN HUMAN MILK
}

\author{
BY \\ I. A. SABRI, M.R.C.P., D.T.M. \& H. (LoND.), \\ AND \\ M. M. FIKRI, B.Sc. (LoND.), M.R.C.S., L.R.C.P. \\ (From the Paediatric Department, Faculty of Medicine, Cairo.)
}

Rickets is a common and important complaint in Egypt. The statistics published by Shawki ${ }^{1}$ show that 50 per cent. of the Egyptian children between the ages of six months and two years have definite clinical manifestations of rickets. Such a high incidence of this disease in a country noted for its clear sky and abundant sunlight is naturally astonishing and the probable etiological factors concerned in the prevalence of this disorder among Egyptian children have been the object of many investigations in the last few years.

In 1932, Sabri and Fikri ${ }^{2}$ experimenting with fat obtained from human, cow's and buffalo's milks (the milks commonly used for infant feeding in Egypt) came to the conclusion that these milks do not contain fully-formed vitamin $D$ in amounts of any practical value in the prevention of rickets. On the other hand, they were able to demonstrate that these milks contain sufficient amounts of the precursor of vitamin D (provitamin D) which after activation by exposure to ultraviolet rays endows these milks with definite antirachitic powers.

The conclusion from the above experiments would be, that the infant, whether naturally or artificially fed, receives most of the antirachitic factor in its milk supply in an inactive form. Unless this factor is activated by exposure of the child to ultraviolet irradiation-obtained from natural or artificial sources-no protection against rickets is provided.

In 1933, Sabri $^{3}$ demonstrated that the amount of ultraviolet radiation in the sunlight of Egypt during the winter and spring seasons is far below that expected from the amount of sunshine. This is due to certain physical and meteorological circumstances. The abundant ultraviolet rays of the summer season are not of great benefit, as the excessive heat interferes with any sufficient exposure of the children to sunlight.

Thus, it is probable that the Egyptian child is not receiving as much ultraviolet radiation as would otherwise be expected. This, undoubtedly, plays an important rôle in the high incidence of rickets in Egypt. 


\section{Present investigations}

The fact that more than 80 per cent. of the Egyptian infants are purely breast fed and that artificial feeding hardly exists in Egypt ${ }^{1}$, facilitates the study of the rôle played by diet in the etiology of rickets in this country. The results of the experiments carried out previously on the vitamin and provitamin D content of the various milks used in Egypt in infant feeding have already been referred to. Our aim in the present experiments has been to find out any difference in provitamin $\mathbf{D}$ content of the milk of mothers living under the same conditions and nursing rachitic and nonrachitic children.

For this purpose milk was obtained from a group of two hundred healthy mothers attending the out-patient department of Foad I Children's Hospital and feeding healthy non-rachitic infants of an average age of six to twelve months and from another similar group of women nursing definitely rachitic infants of the same age as the former group. In both groups, the infants were exclusively breast fed and were not, nor had been, suffering from any general disturbance of any note. The mothers chosen were of the poor, working class coming from the same district of Cairo (Zeinhom) and living under practically the same conditions as regards housing and probably also diet. The percentage of fat in the pooled milk obtained from each group was estimated. The butter was extracted and heated in hot water baths at $40^{\circ} \mathrm{C}$. until it changed to an oily consistency and all the remains of milk together with whey gravitated to the bottom of the container. The fat obtained in this way was exposed to ultraviolet radiation under standard conditions and mixed with the Steinbock and Black rachitogenic diet (No. 2965) in increasing percentages. The idea of using milk fat has been to avoid as far as possible the fallacies that arise from experimenting with whole milk (salt factor) on rats ${ }^{2}$. Albino rats of an average age of from four weeks and 40 grammes in weight were fed on the above rachitogenic diet plus the irradiated fat for a period of four weeks, being kept all the time in total darkness. At the end of that period, the left knee-joints were x-rayed, the animals sacrificed and the phosphorus of the pooled blood of each group was estimated. Throughout the experiment, the rats were weighed regularly. Any rats that did not gain weight properly were discarded.

In reading the skiagrams, the distance between the epiphysis and the diaphysis was measured in millimetres; a distance of less than $1 \mathrm{~mm}$. was considered as slight rickets, between 1 and $2 \mathrm{~mm}$. as moderate, and above $2 \mathrm{~mm}$. as marked rickets. The results obtained are shown in the following table:-

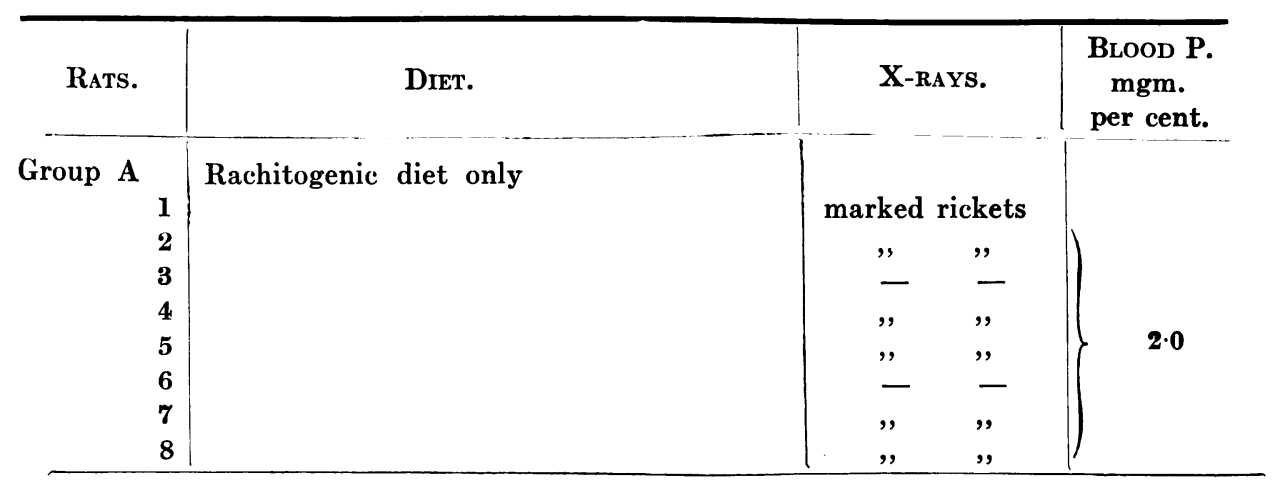




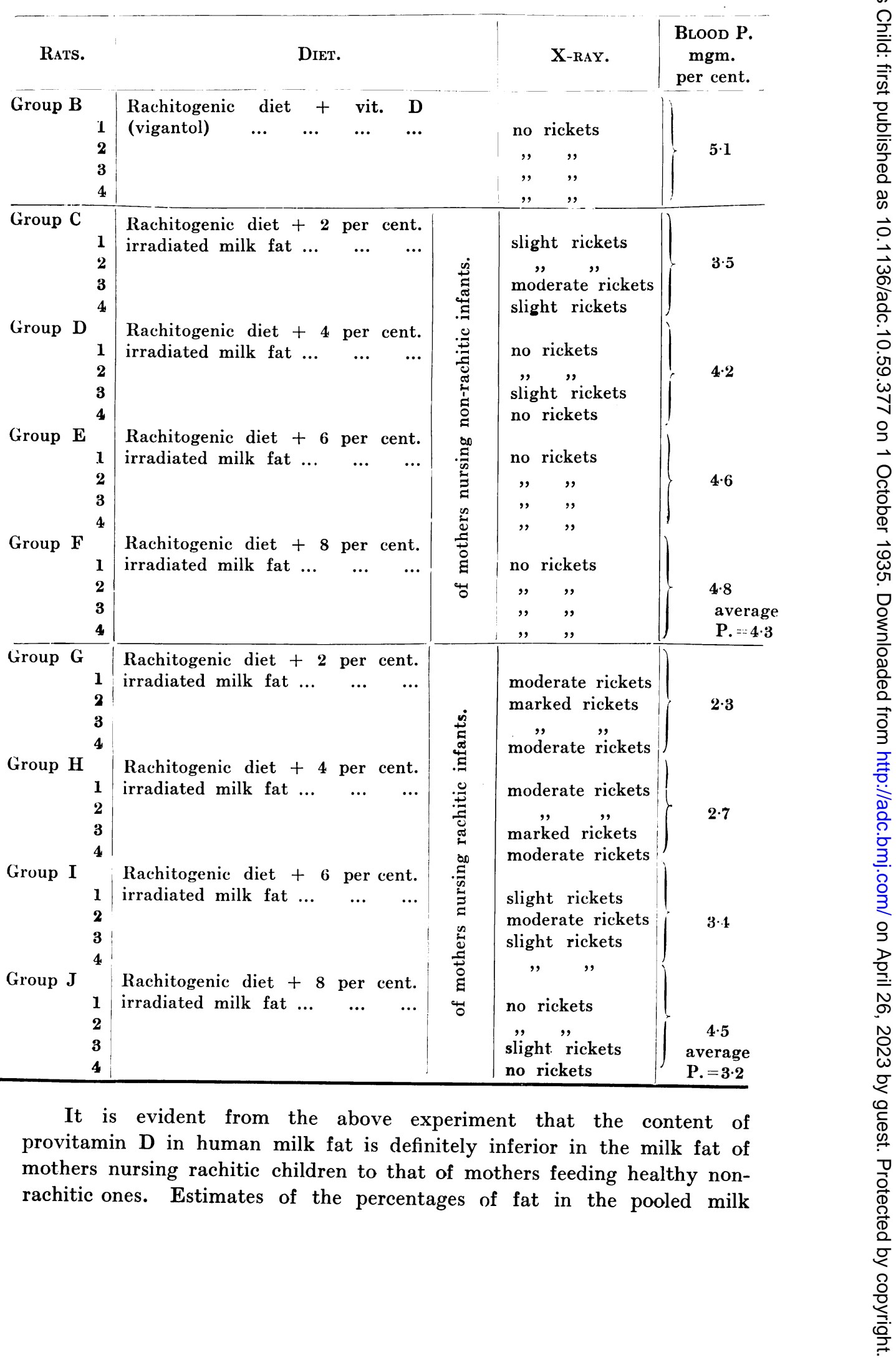


obtained from the two groups of mothers did not show any material difference.

\section{Comment}

Similar results were obtained by us in $1932^{2}$. The material then available, however, was small and the value of the results was limited. In the present experiments, on the other hand, more material was used and greater care was taken in the choice of cases. It should be noted, however, that the difference between the milk obtained from the two groups of mothers was not in the amount of fat but in the content of provitamin $\mathbf{D}$ present. The reason for the difference is not clear and the question requires further investigation.

The conclusions from the above experiments make it probable that the rachitic Egyptian infants, in addition to the deficient supply of ultraviolet rays, receive insufficient amounts of provitamin $D$ in their milk supply. The amount of ultraviolet radiation in Egyptian sunlight seems to be just sufficient to prevent rickets provided that the child receives at the same time a generous supply of provitamin $\mathbf{D}$. If the latter is also defective, rickets develops.

We wish to express our thanks to Dr. S. A. Naga, Radiologist, and Dr. M. A. Abboud, Resident of Foad I Children's Hospital for their great help.

\section{REFERENCES.}

1. Shawki, I., Rep. Internat. Cong. Trop. Med. Hyg., Cairo, 1928, II, 961.

2. Sabri, I. A., \& Fikri, M. M., Arch. Dis. Childh., Lond., 1932, VII, 41.

3. Sabri, I. A., Trans. Third Internat. Paed. Cong. London, Uppsala, 1933, 442. 